\title{
Awareness of Medical Research Ethics among Medical students
}

\author{
Sudheendra Kulkarni, ${ }^{\text {11 }}$ Kumar Sai Sailesh, ${ }^{2}$ Chandrakant Chillarge. ${ }^{3}$ \\ ${ }^{1}$ Tutor \& Nodal Officer for IDSP, Department of Microbiology, Bidar Institute of Medical Sciences, Bidar, Karnataka, India. \\ ${ }^{2}$ Assistant Professor, Department of Physiology, Little Flower Institute of Medical Sciences and Research, Angamaly, Kerala, India. \\ ${ }^{3}$ Professor \& HOD, Department of Microbiology, Bidar Institute of Medical Sciences, Bidar, Karnataka, India.

\section{Abstract} \\ The present study was carried out to observe the knowledge of Medical research ethics among medical students. The study was conducted in the \\ Department of Microbiology, Bidar Institute of Medical sciences, Bidar. 200 male $(n=100)$ and female ( $\mathrm{n}=100)$ second, third \& final year MBBS \\ students were included in the study. The standard questionnaire was used to assess participants' knowledge in research ethics. Knowledge of both male \\ and female students regarding research ethics. In our study we have observed that very few students has knowledge about the research ethics. However, \\ comparatively female students are having better knowledge about research ethics than males. We conclude that overall knowledge about Medical \\ research ethics in medical students was very poor and there is a need to introduce research ethics as one mandatory subject in medical syllabus, as \\ research ethics has applicability. Medical council of India must consider this aspect and introduce a Research ethics department in Medical field along \\ with other departments.
}

Key words: Awareness, Medical Research Ethics, Medical students

\section{INTRODUCTION}

In recent years medical research was increasing all over the world to increase the quality and quantity of life. As medical research involves humans as participants, the researcher must aware of the ethical principles and about ethical committee [1-3]. However, it was reported that research regulations do not exist in many developing countries, and researchers have expressed concerns regarding the extent of individual and institutional research ethics capacity, including the existence of functioning ethics review system. It was reported that research works were carried out without informed consent [4, 5, and 6]. Novelty of the research will definitely depends on the knowledge of the individuals about research ethics. In India there is a CPCSCA, higher authority to regulate animal research. However there is no higher authority to regulate human research. Medical research must continue for the well being of humans and animals and at the same time ethical research is invariably needed. The present study was carried out to observe the knowledge of Medical research ethics among medical students.

\section{MATERIALSAND METHODS}

The study was approved by Institutional Ethics Committee. A written, informed consent was obtained from all the participants. The study was performed in accordance with the "Ethical Guidelines for Biomedical Research on Human Participants, 2006" by the Indian Council of Medical Research and the Declaration of Helsinki, 2008.

\section{Study Design}

The present study was a cross-sectional study

Participants, Inclusion and exclusion criteria

The study was conducted in the Department of Microbiology, Bidar Institute of Medical sciences, Bidar. 200 male $(n=100)$ and female $(n=100)$ second, third \& final year MBBS students were included in the study. The study was approved by institutional ethical committee and free, voluntary,

\section{Address for correspondence* \\ Sudheendra Kulkarni \\ Tutor \& Nodal Officer for IDSP, Department of Microbiology, Bidar Institute of Medical Sciences, \\ Bidar, Karnataka, India.}

written informed consent was taken from all the students prior to the study. Students who are regular to the classes and willing were included in the study.

\section{Inclusion criteria}

Students of both sex and age group between 18-24.

Willing students

\section{Exclusion criteria}

Unwilling students.

The standard questionnaire was used to assess participants' knowledge in research ethics. [7] The first part of the knowledge section consisted of several case scenarios involving the ethics of clinical research in dentistry and asking the respondents to answer questions based on these cases. These cases are as follows.

Case 1 (Informed consent describing risks and benefits). Thirty patients from the outpatient clinic of the Faculty of Dentistry were enrolled in a study that aimed to evaluate the flexible denture base material as compared with conventional denture base. One of the most serious disadvantages of the resilient denture liners is colonization and infection of the material surface by Candida albicans. An oral consent has been taken from the patients without full description of the risks and benefits. Which of the following best describes obligations of informed consent?

(a) The investigators can conduct the research without any ethical responsibility.

(b) A written consent with a brief description of the procedures must be taken.

(c) A full description of the risks and benefits should be stated in the informed consent.

(d) There is no need for informed consent, as the patients were enrolled from the outpatient clinic.

Case 2 (Research involving children). One hundred children of both sexes, age range from 6 to 15 years, were randomly selected from the outpatient clinic of the Faculty of Dentistry. The examined children will be divided into two groups. One group will have their extensively carious teeth extracted, 
while the other group will go through pulpotomy in an attempt to keep the tooth as long as possible in their mouth.

(a)A clear description of the procedure should be explained to the child's parent/guardian.

(b)An assent (oral approval) should be taken from the child.

(c)An assent should be taken from the child as well as a written informed consent from the child's parent/guardian.

(d)No need to have an assent or consent as the children were already enrolled in the outpatient clinic and ready to receive any type of treatment.

Case 3 (Retrospective research on stored samples originally collected for clinical purposes). Fifty patients from the outpatient clinic of the Faculty of Dentistry were diagnosed as having Lichen Planus. Biopsies were taken from the patients after their approval to confirm the clinical diagnosis (patients were not charged any money). A month later, a research on Lichen Planus is planned by the Faculty involving all biopsies that were previously obtained from the patients.

(a) This research cannot be done without the approval of the patients.

(b) The biopsies belong to the faculty of dentistry, so no patient approval is needed.

(c) It is for the researchers to decide whether to take the patient's consent or not.

(d) It is up to the Dean or head of department to decide what to do with the biopsies without patient's interference.

Case 4 (Confidentiality in medical research). Eighty patients from the outpatient clinic were enrolled in a research. The aim of the research was to differentiate between two different treatment modalities in the management of periodontal intraosseousbony defects.

(a) Patients' research files should be coded to ensure patients' confidentiality.

(b) No need for confidentiality as th

e procedures are common in dental practice.

(c) It is left to the investigator to decide whether to keep the research data confidential or not.

(d) The dean or head of the department is the one to decide regarding the provisions of confidentiality.

The correct answer for Cases 1 and 2 is "c," while for Cases 3 and 4 the correct answer is "a." The second part of the knowledge section consisted of the following two questions.

(1)Which of the following are considered guidelines in research ethics?

(a) Nuremberg Code,

(b) Declaration of Helsinki,

(c) Belmont Report,

(d) Council of the International Organizations of the Medical Sciences (CIOMS), or

(e) all of the above.

(2)What do you think is the role of a research ethics committee?

(a) review the ethical aspects of the research,

(b) determine whether informed consent is needed,

(c) review the scientific design of the research,

(d) protect the welfare and rights of the subjects in the research, or

(e) make research more difficult to perform,

(f) other.

Correct answers were "e" for question no. 1 and either (a, $\mathrm{b}, \mathrm{c}, \mathrm{d})$ or (a, b, and d) for question no. 2 .

\section{Data analysis}

Data was analyzed by SPSS 20.0.

\section{RESULTS}

Results were presented in figure no 1 to 3 . Figure 1 presents the knowledge of both male and female students regarding research ethics. In our study we have observed that very few students has knowledge about the research ethics. However, comparatively female students are having better knowledge about research ethics than males.

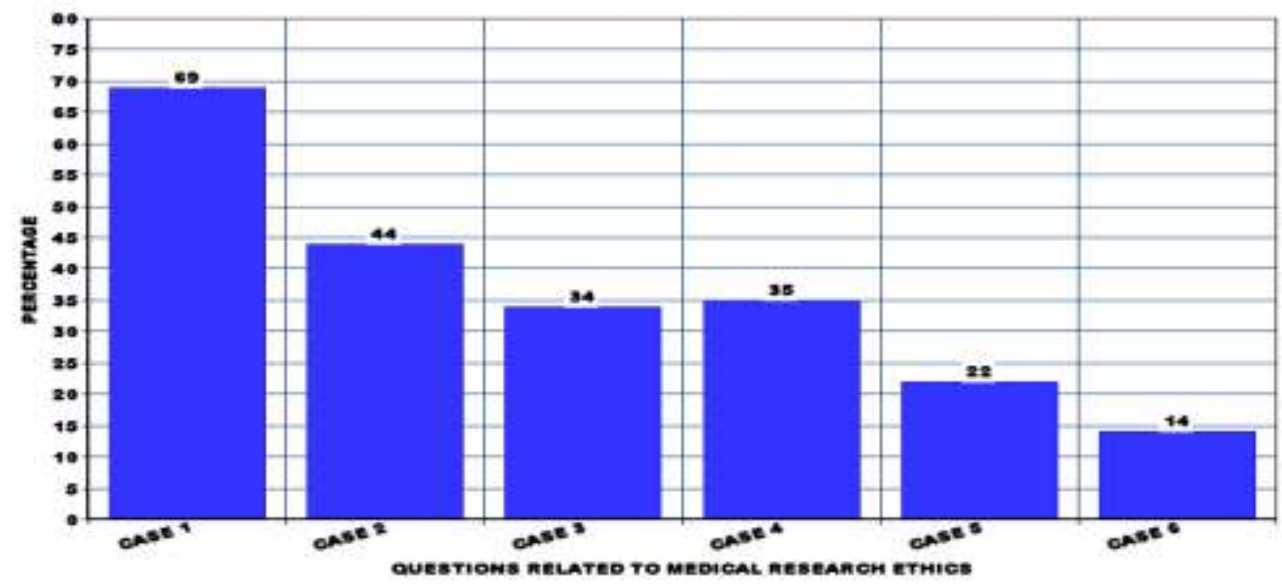

Figure No: 1 Knowledge of Research Ethics in male and female medical students (n=200) ( Values expressed are in percentage. 


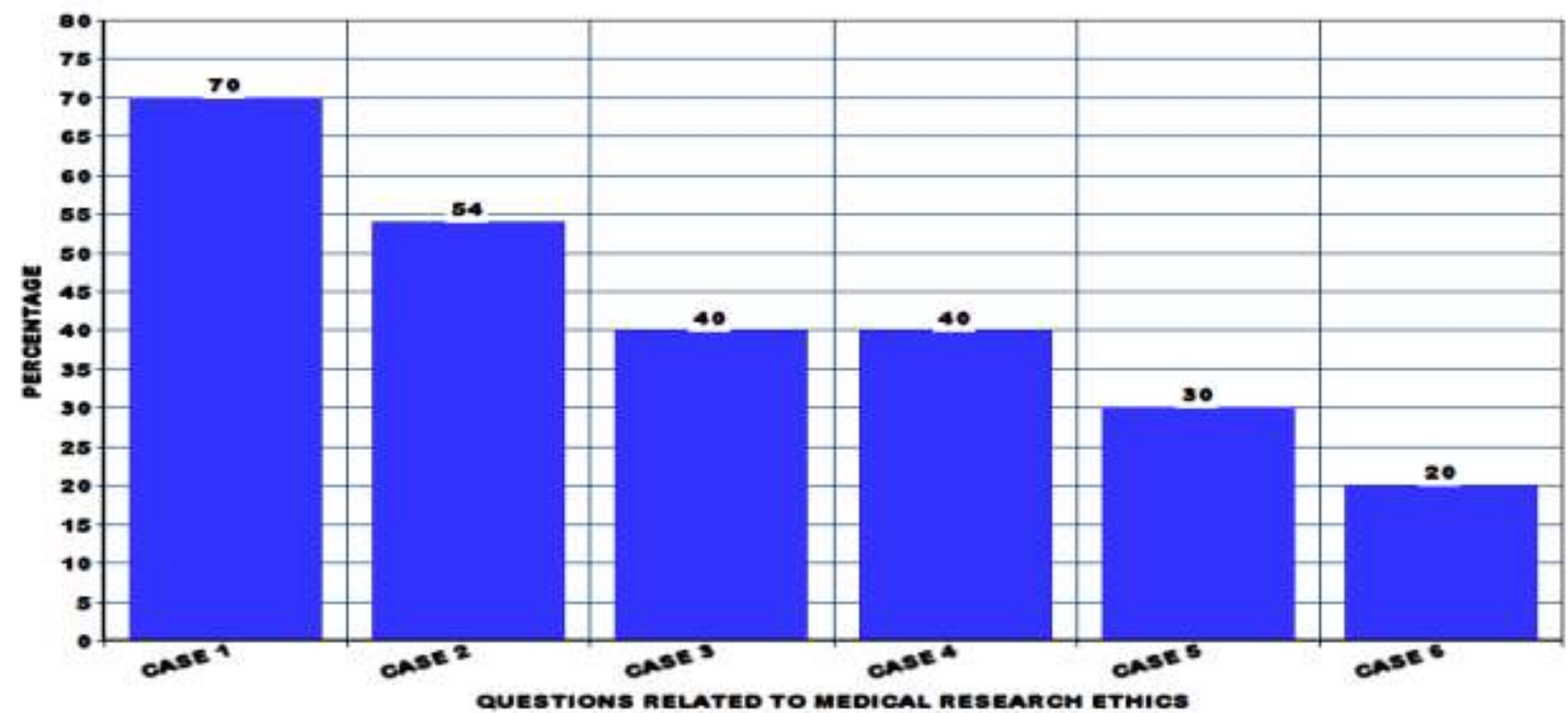

Figure No: 2 Knowledge of Research Ethics in female medical students ( $n=100)$ ( Values expressed are in percentage.)

KNOWLEDOE OF RESEARCH ETHICS IN FEMALE MEDICAL STUDENTS

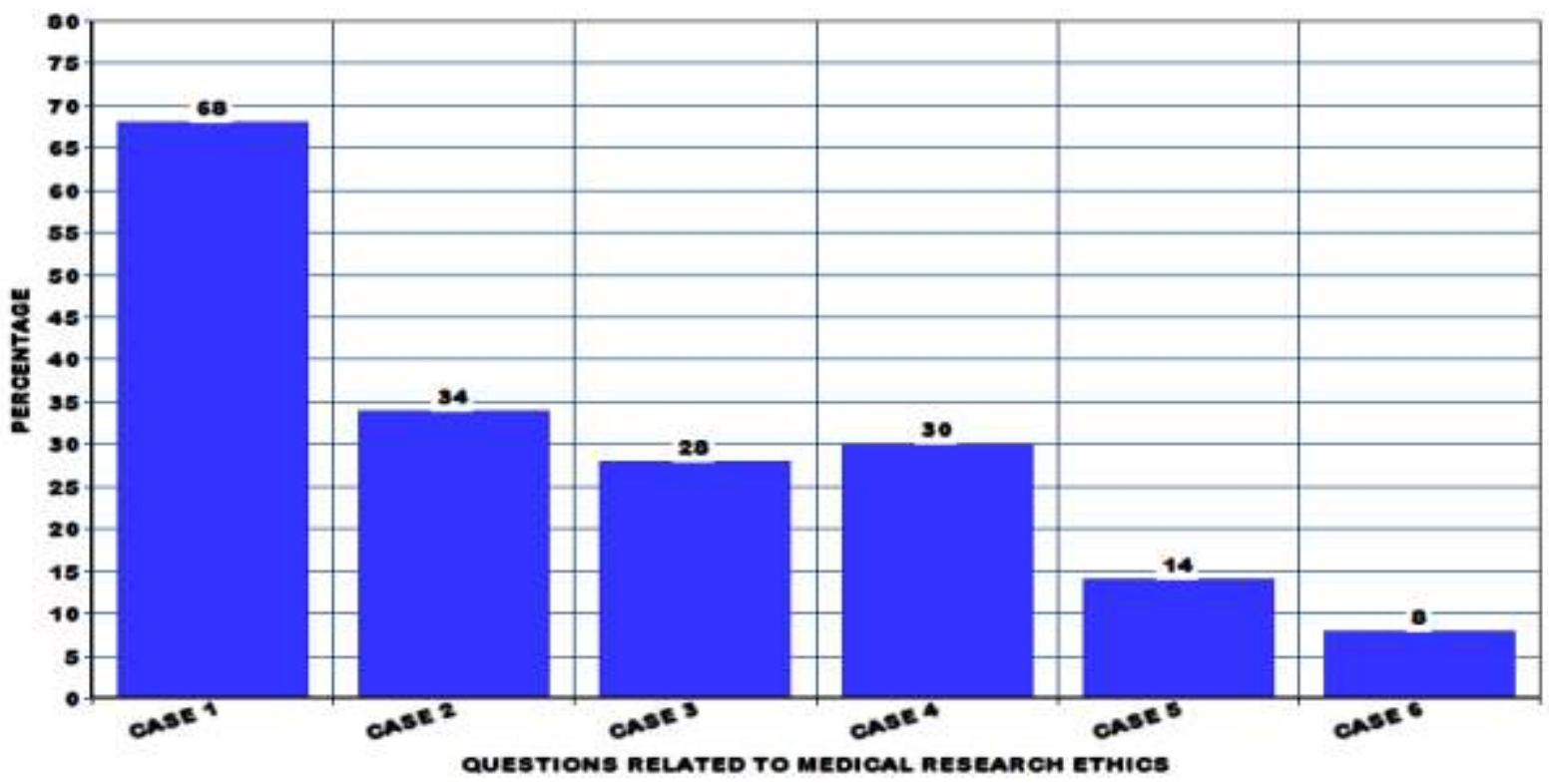

Figure No: 3 Knowledge of Research Ethics in male medical students ( $n=100)$ ( Values expressed are in percentage.)

\section{DISCUSSION}

In the present study most of students has knowledge about informed consent in research. However rest of the knowledge regarding research ethics was poor among medical students. Our study results agree with previous studies.[7] We recommend further detailed studies in this area.

\section{CONCLUSION}

We conclude that overall knowledge about Medical research ethics in medical students was very poor and there is a need to introduce research ethics as one mandatory subject in medical syllabus, as research ethics has applicability. Medical council of India must consider this aspects and introduce a Research ethics department in Medical field along with other departments.

\section{ACKNOWLEDGEMENT}

We would like to acknowledge the Second, third and final year MBBS students of Bidar Institute of Medical Sciences, Bidar for their active participation in the study.

\section{REFERENCES}

1. D. Normile, "The promise and pitfalls of clinical trials overseas," Science, vol. 322, no. 5899, pp. 214-216, 
2008.

2. World Health Organization, "Declaration of Helsinki-Ethical Principles for Medical Research Involving Human Subjects, "2008.

3. Council for International Organizations of Medical Sciences (CIOMS), International Ethical Guidelines for Biomedical Research Involving Human Subjects, Council for International Organizations of Medical Sciences, Geneva, Switzerland, 2002.

4. R. M. Abdur and R. Mamdouh, Ethics in Health in EMRO: Practices and Perceptions Among Health Researchers in the Region, Global Forum for Health Research, 2004

5. M. Abdur Rab, M. Afzal, A. Abou-Zeid, and H. Silverman, "Ethical practices for health research in the
Eastern Mediterranean region of the World Health Organization: a retrospective data analysis.," PLoS ONE, vol. 3, no. 5, p. e2094, 2008.

6. A. Abou-Zeid, M. Afzal, and H. J. Silverman, "Informed consent as an ethical requirement for health research in the eastern mediterranean region of the world health organization," in Proceedings of the Public Responsibility in Medicine and Research (PRIM\&R '06), Washington, DC, USA, 2006.

7. Hadir F. El-Dessouky, Amr M. Abdel-Aziz, Chadi Ibrahim, Malini Moni, Reham Abul Fadl, and Henry Silverman. Knowledge, Awareness, and Attitudes about Research Ethics among Dental Faculty in the Middle East: A Pilot Study. International Journal of DentistryVolume 2011 (2011), Article ID 694759, 13 pages. 